\title{
Medical Informatics Education - Past, Today and Future
}

\author{
Izet Masic ${ }^{1^{*}}$ and Haris Pandza ${ }^{2}$ \\ ${ }^{1}$ Academy of Medical Sciences of Bosnia and Herzegovina, Sarajevo, Bosnia and Herzegovina \\ ${ }^{2}$ Faculty of Medicine, University of Sarajevo, Sarajevo, Bosnia and Herzegovina
}

\begin{abstract}
The development of medical informatics goes back to the second half of the twentieth century with the start of the automation of processes. Medical informatics education plays an important role in the education of health care providers and medical providers. Education in medical informatics is not only important for medical students but also for other medical staff at all professional levels of education. Integrating medical Informatics into the full spectrum of medical education is a vital step required for the understanding and practice of modern medicine. There are curricula in the field of medical informatics at many universities in Europe. Great roles in this field had the International Medical Informatics Association (IMIA) and - the European Federation for Medical Informatics (EFMI). Working groups of IMIA and EFMI defined and recommended concepts and methodologies of education for medical informatics on three levels. Generally in all European countries medical education at universities is
\end{abstract}

organized on the basis of the Bologna concept, which has improved the quality of teaching process in plenty matters, but it has brought a big number of highly educated staff, that are younger than average, but also have average level of knowledge. Basically, the Bologna system has brought averageness we tried to escape from. With the introduction of the Bologna process in Bosnia and Herzegovina and other countries, a new process is being introduced which introduces a new curriculum, a greater number of subjects, a complemented systematization of knowledge and the need to correct past attitudes. Since the curriculum of medical informatics varies between countries and universities and faculties in the country, it is necessary to take steps towards the unification of the curriculum at the international level. Aim of the article is to show the status of medical informatics education in Bosnia and Herzegovina and Europe.

Keywords

Medical informatics; Education; Curricula

\section{Correspondence to:}

\section{Prof Izet Masic, MD, PhD, FEFMI, FACMI, MIASHI}

Academy of Medical Sciences of Bosnia and Herzgovina, Sarajevo,

Bosnia and Herzegovina,

E-mail: izetmasic@gmail.com
EJBI 2018; 14(2):40-45

Received: March 11, 2018

Accepted: March 17, 2018

Published: April 30, 2018

\section{1}

\section{Introduction}

The development of medical informatics goes back to the second half of the twentieth century with the start of automation of processes $[1,2]$. The need for additional education of health professionals was felt after the first applications of electronic data manipulation [3, 4]. For physicians in primary health care and in clinics, in order to perform their duties in a high quality manner, must be up to date with the latest accomplishments in medicine and health. Several different schools of Medical informatics were established in the world: by Morris Collen in USA, by William Abbott in UK, by Francois Gremy in France, by Peter Leo Reichertz in Germany, by Gjuro Dezelic in former Yugoslavia, etc. $[1,2]$. Since the 60 's the development of information technologies has had a quantitative and qualitative growth especially in diagnostics and therapy, and health workers had to follow that [3]. A great role in this field had the International Medical Informatics Association (IMIA) and - the European Federation for Medical Informatics (EFMI). Working groups of IMIA and EFMI recommended and defined concepts and methodologies of education for medical informatics on three levels [5].

In Europe, EFMI is the leading organization in medical informatics and represents 32 countries. EFMI was founded in 1976 [5].

The national associations/societies for Medical Informatics in Europe and other parts of the world, linked by IMIA and its branch offices, are engaged in the organization of international and regional gatherings and congresses, where experiences and strategies are exchanged. Also, some medical informatics societies have launched journals dealing with themes in the domain of medical informatics [1]. 


\section{Medical Informatics - Educational Concepts}

Medical informatics education plays an important role in the education of health care providers and medical providers [5]. Education in medical informatics is not only important for medical students but also for other medical staff at all professional levels of education. The advent of healthcare reforms and the rapid application of new technologies have resulted in a paradigm shift in medical practice. Integrating medical informatics into the full spectrum of medical education is a vital step required for the understanding and practice of modern medicine [1]. There are curricula in the field of medical informatics at many universities in Europe. Bachelor's Degree Program in Medical Informatics can be attended at 14 universities in Germany following the concept of medical informatics education proposed by Peter Leo Reichertz who proposed the term Medical Informatics in the scientific literature in 1972. Specialization provides graduates who can develop IT solutions. These specializations are not part of curricula of medical faculties or related faculties, but an independent study that is primarily oriented to medical informatics as a major study program. They can develop medical imaging techniques as well as diagnostic procedures and organize the management of patients' data. For this purpose, the basics of computer science are taught. These include, for example, programming, mathematics and statistics, algorithms and data structures or the development of databases [2].

The competence for the development of customized programs, software engineering, is also taught. Basic education also includes fundamental medical knowledge in the most important areas, and diagnostic and therapy systems [2].

Modern information technologies play a major role in the work of doctors after the completion of medical studies. Physicians are faced with a large amount of information that needs to be processed. Based on such information, decisions need to be taken that are essential for the further treatment of patients. The ease with which doctors can retrieve the relevant information they will use to treat patients plays an important part in everyday practice (Table 1).

\section{The Bologna Process and Medical Informatics}

The Bologna process introduces standards and norms that include the duration of study and weekly workload in teaching and overall work needed to master some skills, so that there is no arbitrariness. Under this process, the duration of study is divided into three clearly defined segments: undergraduate, postgraduate and doctoral graduate studies, which have a precisely defined duration [4].

The Bologna declaration has improved the quality of the teaching process in plenty matters, but it has brought a big number of highly educated staff, that are younger than average, but also have an average level of knowledge. Basically, the Bologna system has brought averageness we tried to escape from. The solution of this can be in setting higher standards and better outcomes of education by using new available technologies that can contribute to higher quality of teaching $[6,7,8,9$, $10,11]$. These technologies include distance learning, online teaching, and online student testing. This implies creating a set of items that covers all areas of a subject that students answer and then receive immediately the response whether the answer is correct or not. The student can immediately see the text of the textbook relating to the given question. Although this method is efficient, it requires a great effort from the teaching staff that needs to create a large number of questions and answers that students have to manage. The Bologna process has brought a new curriculum, contributing to the engagement of a greater number of teaching staff and a new way of presenting knowledge to the student, who more acts in the role of a passive observer in the education process [6]. We don't expect an instant solution of the aforementioned problems, but in the long term, this process could lead us to increasing quality, which would bring us closer to modern developed countries and their education systems. We shouldn't forget that knowledge is the most powerful weapon in the world, and its use is the path to prosperity and progress in community.

Bosnia and Herzegovina signed the Bologna declaration on 18 September 2003 in the light of this new approach to university education, and the process of joining the European Union. In order to investigate the effects of the Bologna declaration on the education process, Masic et al. set the following aims for research [7].

- To determine the current level of knowledge among medical students at the Medical Faculty of the University of Sarajevo after the declaration was implemented in comparison to pre-Bologna students.

- To determine the level of knowledge among medical students before their enrolment at the faculty compared with pre-Bologna students.

- To find out students' opinion on their needs for further education.

Conclusion of research was that a) Continuous quality of education must be assured (use of internal and external evaluation); b) Medical curriculum needs to be adjusted with the curricula used in EU member states where quality assurance is significantly implemented; c) University teachers and staff must be evaluated regularly; e) Medical students must be involved in all the reform processes; f) Volume and content of the practical medical education must be improved; g) Library services must be improved and educational facilities must be equipped for use of information technology [8]. 
After the Bologna declaration, medical informatics has become an integral part of all curricula in the field of health studies at medical and related faculties. However, there is no single program for all faculties of individual universities, both at national and international levels. Interesting differences exist both within and between countries and programs with regard to curricula structures and expected learning outcomes. Several initiatives have been launched in the last years to define some standardized content of curricula, aiming at developing sample medical informatics curricula $[6,7,8,9]$.

\section{Medical Informatics Curricula (Example of Bosnia and Herzegovina)}

Many universities are organizing teaching programs for medical students in medical informatics. The start of the study in medical informatics as part of curricula for medical students is not the same in all Universities. One prefers to start medical informatics in the first or second year of study while the other prefers teaching medical informatics in the final year.

Medical informatics is being studied at several faculties within a university, e.g., Faculty of Medicine, Faculty of Dental Medicine (Stomatology), Faculty of Pharmacy, and Faculty of health studies (bachelor program). Master studies and doctoral studies also include curricula in the field of medical informatics. Here is the list of State Faculties at Universities in Bosnia and Herzegovina where medical informatics is studied (Table 1).

In Bosnia and Herzegovina we encounter a great variety of curricula between universities as well as at different faculties of the same university. First of all, there is a difference in the title of the subject. The most commonly used title of the subject is medical informatics. However, the curricula at the Sarajevo University's Faculty of Health Studies, at the Mostar University's Faculty of Health Studies, and at the Faculty of Medicine of the University of Tuzla combine medical informatics and statistics as one subject. The University of Mostar on the other hand combines the methodology of scientific work and biomedical information technology as one teaching subject. The other variants of the name of the subject are: Informatics; Informatics in healthcare; scientific methodology and medical informatics; Methodology of scientific work and biomedical information technology; Informatics in medicine; and Informatics with medical statistics. The total number of earned ETCS points as well as the number of practical lessons and lectures varies considerably among faculties (Table 1).

\section{$5 \quad$ Medical Informatics Education Today}

Informatics education begins in elementary school so that students at the moment they start their study at the university have already some basic knowledge. Further education of information technologies during studies at biomedical faculties is aimed at a better management of medical information. Since students are confronted with a large quantity of information that they have to deal with at the end of their studies, medical informatics plays an increasingly important role. The outcomes of learning after education in medical computing therefore make up a significant part of the skills taught during the studies at biomedicine faculties. These skills will greatly assist future medical workers in treating patients, e.g., in solving current problems and in the process of medical decision making.

Many older medical workers are faced with the need to use computers to enter and process data and to create various statistical reports, although they did not have the opportunity to have formal education in medical informatics during their studies. Young healthcare professionals who pass education in medical informatics during the course of study can help in such cases to overcome these obstacles.

The time to begin education in medical informatics at universities is still not precisely defined. Most faculties prefer to start education in the first year of study so that the acquired skills can be applied by students during the studies of the biomedical faculty. On the other hand, a smaller number of biomedical faculties believe that some of the finishing years are ideal for education in medical informatics, because only then do students master medical knowledge to be processed using a computer.

Medical informatics courses can also be divided into two parts where the basic skills in medical informatics would be taught in the first years of study and applied medical informatics in the last year of the study after obtaining the necessary medical knowledge $[12,13,14,15]$. This applies in particular to aspects of medical informatics such as medical decision-making, classification systems, health information systems, and similar issues. This concept acknowledges that only people with profound medical knowledge can fully understand those issues. Faculties where medical informatics is studied are Faculty of Medicine, Pharmacy, Health Care, and Dentistry.

The development of modern technology and the Internet have enabled the explosive growth of distance learning (DL) $[14,15,16]$. DL is a process in education that focuses on educating students who are not physically present in the traditional classrooms or the student's campus. It is described as a process where the source of information is separated from the students in space and time [10]. Due to a legal obstacle, it is not possible in Bosnia and Herzegovina to organize distance learning because students must be present in the class. DL can still be used for online learning so that students can get assignments from teaching staff and send documents containing solutions to task sets (seminar papers, presentations and the like).

Universities and other educational institutions as well as the government share responsibility for guaranteeing high standards and quality of medical education. 
Table 1. The names of subject, semester, works hours and etc. points at state universities in Bosnia and Herzegovina.

\section{University and Faculty}

Sarajevo University

Faculty of Pharmacy

Faculty of Medicine: two different studies:

- In Bosnian

- In English

Faculty of Dentistry

Faculty of Health Studies (Bachelor program)

\section{Tuzla University}

Faculty of Medicine

Department of Health Study of Faculty of Medicine (Bachelor program)

\section{University of Zenica}

Faculty of Medicine

Faculty of Health (Bachelor program)

\section{University of Bihać}

High School of Health (Bachelor program)

\section{East Sarajevo University}

Faculty of Medicine - Foča

Faculty of Health (Bachelor program)

\section{University of Mostar}

Faculty of Medicine

Faculty of Health Studies (Bachelor program)

Faculty of Pharmacy

\section{Name of Subject}

Pharmaceutical

informatics
Total work Hours

$(\mathrm{L}+\mathrm{P})$

$30+30$

$15+15$

$15+30$

$20+10$

$40+15$

$30+30$

$40+15$

$30+15$

$30+15$

Medical informatics

III

$30+15$

Informatics in Healthcare I

$30+30$

Informatics in Medicine II

$15+15$

$15+30$

Informatics in Healthcare I

Scientific methodology and medical informatics

Health information

system and medical statistics

Methodology of scientific work and biomedical IX information technology
3.5

2

4

1

3

4

2

2

2

6

5

4

5

(1)

10

ETCS

The aim of medical education is to educate doctors and other health care professionals who are entitled to practice their profession with no restrictions, based on what they learned [3, 5]. The first professional degree means completing a curriculum which qualifies the student for a range of different choices in his/ her career, including the treatment of the diseased, public health service, clinical and basic research, or further medical education. One of the significant approaches to education is learning by doing. Any further career choice requires additional education apart from that leading to the first professional degree $[4,5]$. The university is responsible for creating an academic environment where learning and research can progress in an optimal manner.
To improve medical knowledge and to provide the best quality of health protection, active medical research as such has to be carried out under academic conditions in order to meet the highest medical standards [3].

Teaching of medical informatics should be a collaborative effort to expose students to a variety of medical information management applications. The medical informatics educational model has a modular format so that students can work with a variety of realistic situations and become enthusiastic users of computer-based medical information systems. All faculties should introduce appropriate concepts and systems, and engage faculty staff to guide students in the 
use of medical information systems. What should be integrated into the required curriculum is a matter of decision. A basic medical education principle includes education leading to the first professional degree (the title of the General Practitioner or GP), clinical education as preparation for general medical practice or specialty, and obligatory continuous, life-long education of each doctor.

The quality of the teaching/learning process depends mainly on infrastructure that includes an optimal teaching space, personnel and equipment in accordance with existing standards and norms at the cantonal or entity level at universities, which are required to adequately implement the educational curriculum for students from first to sixth year based on the Bologna concept. Such infrastructure needs adequate funding $[12,16]$.

\section{Perspectives for Future Development of Medical Informatics}

In the future, the medical informatics curriculum should be standardized to overcome the apparent difference in the programs. There are also differences in the number of ETCS points earned at some faculties. It is necessary to determine which areas of medical informatics are required for certain medical workers. To advance international cooperation and dissemination of information in medical informatics on a European basis is essential to achieve these tasks. In the future, high standards in the application of medical informatics should be promoted. Further development of medical informatics as well as education in medical informatics is an important factor for improving the level of teaching at the biomedicine faculties. High standards in education in medical informatics should been encouraged through standardization and taking into account the emerging IT technologies.

For education in medical informatics the following kinds of learning outcomes can be identified. They assure that graduates from such programs know at least the basics of those related biomedical and health informatics disciplines and to give various programs the flexibility to focus on one or more of those overlapping areas such as biomedical engineering, medical information sciences, molecular biology or nano-sciences, depending on the cultural, scientific and technical context of the institution [9].

Distance learning in medicine has impact on telemedicine and practicing medicine as well. Basic skills at the use of computers and networks must be a part of all future medical curricula. The impact of technical equipment on the relation between patient and doctor must be understood, because the situation where the diagnosis based on live voice or picture is different from a normal doctor-patient contact [12].

E-Learning, by definition, is using electronic learning aids which in our case may be a computer, PAD device or smartphone. As an integral part of E-Learning, distance learning stands out.
Along with favoring knowledge as the most important global resource for the future, in the last decade extensive work has been performed on improvement and expansion of all forms of electronic support of the educational process [15].

Online tests and quizzes are one of the aspects of distance learning that are based on student interaction with the system. The system has stored the correct answers to these questions and explanations of the correct answers. When a student answers all questions, he/she can immediately see where a mistake is made and can take a second test until all the answers are correct. Additional statements explain why the answer is correct or not [12]. Distance learning should ensure high educational standards to students and teaching staff, and can help medical staff to develop "Lifelong learning way of life" $[13,15]$.

Managing a medical database should be a very important skill of medical workers in future. A medical database enables doctors to have better insight into the success of the treatment of individual patients and to determine whether certain methods of treatment are better than other ones. A comprehensive database enables us to make matches between any two or more groups of patients. A medical record is an important set of data that is designed to store information of all the events related to a specific patient and facilitate later data retrieval $[1,14]$. Another important function of medical records is its use to evaluate diagnostic procedures or the outcome of some therapeutic and surgical procedures. Even with the help of medical records, these goals cannot be easily achieved. Old fashioned paper medical records that keep all of one patient's files in one folder (envelope) represent the traditional way of data collecting [2].

Nomenclatures and classifications are an essential part of scientific methodology in the health care. The existing state of the nomenclature of healthcare activities enables the optimal application of computer technology in processing and retrieval of medical data or information [2]. In the future, emphasis should be put on understanding and processing of data based on the use of medical classifications. Another more modern way of keeping patient records is a computer database that uses a medical classification such as the International Classification of Diseases, Injuries and Causes of Death (ICD). Now, it is possible to search the patient record more rapidly, but a patient can only access this data while he is in the physician's office. Medical records that form an integral part of information systems of individual countries are easy and comprehensive medical record keeping software for maintaining ones family's medical history. This way, a medical record can even better utilize ICD classification because there is more relevant information that is necessary to code specific disorders [2].

Forming interdisciplinary studies at universities will bring together medical professionals and information technology specialists who will educate a staff with knowledge in both 
areas and so better respond to the needs of healthcare institutions. Such curricula are already normal in Germany, Austria and Switzerland and should be included in all university curricula.

\section{Conclusion}

Bologna's model of education at biomedical faculties in Bosnia and Herzegovina, since its introduction into practice 15 years ago, has not lead to the unique curriculum for most of the subjects, including the subject of medical informatics. The most integral syllabus of medical informatics, mostly in accordance with the recommendations of IMIA and EFMI, was introduced by the Sarajevo Medical Faculty in 1992. Unfortunately, the changes and amendments in the curricula resulted in the reduction and loss of the medical informatics subject in terms of teaching hours in theoretical and practical courses in individual study fields, as happened during the last 15 years in four fields of study programs. Students studying according the old system have the right to complete their studies by 2020 according to the program they started to study, and since 2002, the Bologna model controls the process. Since 2014, there has been a study of medicine in English. Furthermore, at some faculties, the fund of teaching hours for medical informatics was reduced, and sometimes the subject was even excluded from the syllabus. Medical informatics as a scientific and academic discipline has a great impact even prior to the modern era of information technologies. But, especially since it is becoming increasingly important in every day's modern medicine, where the application of information technologies has been rooted as the basis for all three levels of health protection in diagnostics and therapy through electronic documentation, management, clinical decision-making using software solutions and expert systems, etc. The use of information technologies has altered the science-research world. Modern science so without a database, would probably make no sense. Medical professionals are confronted by data processing in all spheres of activities using multiple software solutions for their everyday work.

The Bologna process in Bosnia and Herzegovina has minimized the importance of medical informatics and has also led the academic community to a very unfavorable position. While aiming at improving the quality of education itself, improving the level of quality of graduated doctors and getting extraordinary medical professionals, there is just a gain in quantity, neglecting quality. Reform is necessary in many segments, and it includes education in the field of medical informatics for all three levels of studies. Medical informatics should be perceived as essential in the digital world of modern medicine.

\section{References}

[1] Masic I, Novo A. History of Medical informatics in Bosnia and Herzegovina. Acta Inform Med. 2007; 15: 49-61.

[2] Zvarova J, Masic I. Medical informatics - an interdisciplinary approach. Med Arh. 1996; 50: 107-109.
[3] Masic I. Medical informatics education in Bosnia and Herzegovina. Yearb Med Inform. 2004: 192-196.

[4] Masic I. Medical Informatics as Academic and Scientific Discipline in Bosnia and Herzegovina - Twenty Five Years of Experiences from Faculty of Medicine, University of Sarajevo. Acta Inform Med. 2017; 25: 85-87

[5] Mantas J, Ammenwerth E, Demiris G, Hasman A, Haux $\mathrm{R}$, Hersh W, et al. Recommendations of the International Medical Informatics Association (IMIA) on education in Biomedical and Health informatics. Methods Inf Med. 2010; 49: 105-20.

[6] Masic I, Novo A, Deljkovic S, Omerhodzic I, Piralic A. How to assess and improve quality of medical education: Lessons learned from Faculty of medicine in Sarajevo. Bosn J Basic Med. Sci. 2007; 71: 74-78.

[7] Masic I, Begic E. Efficiency of Implementation of the Bologna Process at Medical Faculty, University of Sarajevo. Mater Sociomed. 2015; 27: 67-70.

[8] Masic I. Quality assessment of medical education at Faculty of medicine of Sarajevo University. Med Arch. 2012; 66 (3 Suppl 1): 6-10.

[9] Masic I, Begic E. The Actual (Un)usefulness of the Bologna Systsem in Medical Education. Med Arch. 2016; 70: 158-163.

[10] Masic I, Ciric D, Pulja A, Kulasin I, Pandza H. Quality Assessment of Medical Education and Use of Information Technology. Stud Health Technol Inform. 2009; 150: 898-902.

[11] Masic I. Quality assessment of medical education at faculty of medicine of Sarajevo university - comparison of assessment between students in Bologna process and old system of studying. Acta Inform Med. 2013; 21: 7682.

[12] Pandza H, Masic I. Distance learning perspectives. Acta Inform Med. 2010; 18: 229-232.

[13] Masic Z, Novo A, Masic I, Kudumovic M, Toromanovic S, Rama A, et al. Distance Learning at Biomedical Faculties in B\&H. Stud Health Technol Inform. 2005; 116: $267-72$

[14] Masic I. E-learning as new method of medical education. Acta Inform Med. 2008; 16: 91-100.

[15] Masic I, Pandza H, Kulasin I, Masic Z, Valjevac S. Teleeducation as method of medical education. Med Arh. 2009; 63: 350-353.

[16] Masic I, Sivic S, Pandza H. Social networks in medical education in Bosnia and Herzegovina. Mater Sociomed. 2012; 24: 162-164. 